Systematic Review

\title{
The Effect of Early Use of Supplemental Therapy on Preventing Postherpetic Neuralgia: A Systematic Review and Meta-analysis
}

Xiu-Fang Xing, PhD, Zhen-Feng Zhou, PhD, Feng-Jiang Zhang, MD, and Min Yan, MD

From: Department of Anesthesiology, the Second Affiliated Hospital of Zhejiang University, School of Medicine, Hangzhou, China

Address Correspondence: Min Yan, MD Jiefang Road 88 , Hangzhou, China

E-mail: zryanmin@zju.edu.cn

Disclaimer: There was no external funding in the preparation of this manuscript. Conflict of interest: Each author certifies that he or she, or a member of his or her immediate family, has no commercial association (i.e., consultancies, stock ownership, equity interest, patent/licensing arrangements, etc.) that might pose a conflict of interest in connection with the submitted manuscript.

Manuscript received: 02-16-2017 Revised manuscript received: 03-26-2017

Accepted for publication: 03-30-2017

Free full manuscript: www.painphysicianjournal.com
Background: Postherpetic neuralgia (PHN) is the most common and refractory complication of herpes zoster $(\mathrm{HZ})$. Aggressive treatment of acute pain in $\mathrm{HZ}$ has the potential to prevent the development of PHN, but the preventive efficacy of supplemental therapy commonly used in clinical practice is controversial.

Objectives: Our aim is to examine the efficacy of supplemental therapy in preventing PHN.

Study Design: A meta-analysis.

Setting: All of the selected studies are randomized controlled trials (RCTs).

Methods: A systematic and comprehensive database search was performed in CENTRAL (1976 to March 2016), MEDLINE (1977 to January 2016), and EMBASE (May 1980 to December 2016). According to the selection criteria, data of the included studies were extracted by 2 independent reviewers. RevMan 5.3 (The Nordic Cochrane Centre for The Cochrane Collaboration, Copenhagen, Denmark) was used to perform this meta-analysis.

Results: Nine trials, with a total of 1,757 participants (888 in the treatment group and 867 in the control group), were included in the final analysis. Of the 9 trials, 3 compared systemic adjunct therapies with the control, and 6 trials compared interventional procedures with the control. The early use of supplemental therapy was associated with a significantly less incidence of PHN in 3 months after acute rash presence (RR $0.53,95 \% \mathrm{Cl} 0.34$ to $0.81, P=0.004)$. The systemic adjunct treatments subgroup was not found with any benefit (RR $0.76,95 \% \mathrm{Cl} 0.46$ to $1.26, P=$ 0.29). A significant decrease in visual analog scale (VAS) score was reported in all of the 9 trials when compared with baseline, but the decrease slopes of the pain scores between the treatment group and the control group were similar in 5 trials. The most common adverse events in systemic adjunct treatments group were dizziness, nausea, dyspepsia, and dry mouth. The interventional procedures group was associated with procedure-related complications such as mild hypotension, voice change, dysphagia, drowsiness, and headache.

Limitations: There were only a few RCTs and most of them lacked adequate allocation concealment and blinding. Further, the English-only approach might have omitted trials published in non-English journals. Finally, some of the secondary outcomes of data were insufficient for meta-analysis, and future studies are warranted.

Conclusion: This meta-analysis demonstrates that the early use of supplemental therapy can significantly reduce the incidence of PHN. The subgroup analysis shows that supplemental interventional procedures have a beneficial effect on preventing PHN, while supplemental systemic adjunct treatments do not. The early use of interventional procedures for acute pain may be a preferred choice for patients without contraindication, but evidence is moderate. More data from high-quality RCTs will be needed to confirm these results.

Key words: Postherpetic neuralgia, systemic treatment, local anesthesia, analgesia, meta-analysis

Pain Physician 2017; 20:471-486 
H erpes zoster $(\mathrm{HZ})$ results from reactivation of the latent varicella zoster virus (VZV) in sensory ganglia, with characteristic symptoms of a painful skin rash and localized blisters (1). At the initial stage of infection, commonly in childhood, VZV causes varicella (chickenpox) $(2,3)$. After the initial infection, VZV remains inactive in the sensory nerve ganglia of the host across its lifetime. When the host is aging or has poor immune function, the latent virus will reactivate and cause $\mathrm{HZ}$. The $\mathrm{HZ}$ rash is often accompanied with continuous or episodic sensory sensations such as pain, paresthesia, dysaesthesia, allodynia, or hyperesthesia $(1,4)$. Usually, the rash heals and the pain resolves within 2 to 4 weeks, but in some patients the pain continues to persist for more than 90 days after the onset of the rash (5), which is known as postherpetic neuralgia (PHN).

$\mathrm{PHN}$ is the most common complication of HZ. Depending on the definition, the incidence of $\mathrm{HZ}$ patients developing PHN varies from approximately $5 \%$ to $30 \%$ (6). The continued pain or paresthesia not only affects the patient's quality of life, but also causes physical disability, emotional distress, and social isolation. Advanced age is already known as one of the risk factors of developing PHN. The cumulative incidence increases from $2 \%$ in $\mathrm{HZ}$ patients less than 50 years old to about $20 \%$ in those over 50 years old and reaches to $50 \%$ in those more than 85 years old (7-10). Therefore, a significant health burden is expected to surge considering the trend of aging and the increasing number of patients with PHN (6).

Conventional treatments for PHN include topical lidocaine or capsaicin, anticonvulsants, tricyclic antidepressants, and opioids $(11,12)$. However, whether prescribed alone or in combination, these medications only partially work in some patients while invalid for others. Once PHN presences, it is often refractory to the treatment. Therefore, it is important to prevent the occurrence of PHN. Previous studies have identified age, rash duration before consultation, presence of a severe rash, and acute pain severity as predictors of increased PHN risk (13-15). Thus, the treatment of acute pain caused by $\mathrm{HZ}$ has the potential to prevent the development of PHN $(16,17)$.

Due to the inflammation of ganglion and the tissue damage caused by virus replication, which played an important role in the pain during acute $\mathrm{HZ}$, antiviral medicines and corticosteroids were prescribed at the first appearance of the rash and were thought to be promising in preventing PHN for decades. Several trials have found that antiviral agents and corticosteroids appeared to be effective in reducing the severity of symptoms associated with acute $\mathrm{HZ}$ and PHN severity and its duration (18-20). However, the recent Cochrane Reviews indicate that antiviral agents and oral corticosteroids have no effect in reducing the incidence of PHN $(21,22)$.

The 3-step WHO pain ladder is recommended by the European guidelines to treat the acute $\mathrm{HZ}$-associated pain: in situations of mild pain intensity, non-steroidal anti-inflammatory drugs (NSAIDs) or other nonopioids are appropriate; for moderate pain, nonopioids in combination with weak opioid analgesics might be sufficient; for severe pain, nonopioids combined with strong opioids may be required (23). In clinical practice, physicians prefer to add supplemental therapy to control acute moderate-to-severe pain, though these methods have not been recommended or mentioned in the European guidelines.

Considering the neuropathic component of pain, tricyclic antidepressants (e.g., amitriptyline) or antiepileptic drugs (e.g., gabapentin, pregabalin) were used. In addition, it is believed that $\mathrm{HZ}$ mainly affects the sensory ganglia and adjacent neuronal tissues. The repetitive painful stimuli to the central nervous system might lead to central sensitization of the nociceptive system and subsequently produce chronic pain (24). Thus, interventions aimed at prohibiting the painful stimuli transportation and reducing the inflammation in this area may prevent PHN. In this respect, sympathetic nerve blocks and intrathecal and epidural analgesia have been utilized to treat the pain caused by $\mathrm{HZ}$ and PHN $(25,26)$. Although these supplemental therapies have been commonly performed in clinical practice, their efficacy in preventing PHN remains controversial.

Some studies reported that acute pain management, such as oral gabapentin or pregabalin, can significantly reduce the pain severity 6 hours after medication administration $(27,28)$; however, the longterm outcomes were lacking. One trial reported that oral oxycodone or gabapentin can reduce the mean worst pain over 8 days and 14 days compared to the placebo group, but there was no difference between the groups at 28 days (29). Another 3 studies evaluated the effect of different pain managements for preventing PHN. One trial showed that early administration of pregabalin for $\mathrm{HZ}$ can reduce the incidence of $\mathrm{PHN}$ (30), but this was a retrospective study. An additional 2 RCTs showed that pregabalin and gabapentin did not have a significant effect on the relief of acute $\mathrm{HZ}$ pain or the reduction of PHN incidence when compared to the control group $(31,32)$. Except for oral analgesics, 
interventional procedures are another common applied method. A single paravertebral injection and stellate ganglion blockade were proved to be effective to prevent the development of PHN $(31,33)$. However, a large RCT showed that a single epidural injection of steroids and local anesthetics during the acute phase of $\mathrm{HZ}$ has a mild effect on reducing $\mathrm{HZ}$-associated pain within one month, but has no effect on preventing PHN for a long period of time (34).

Despite the lack of clear evidence, supplemental systemic adjunct treatments or interventional procedures are commonly used to reduce the acute pain of $\mathrm{HZ}$, considering that any intervention that reduces the duration or intensity of this pain is promising in preventing the development of PHN. This meta-analysis aims to systematically review all of the RCTs that evaluate the efficacy of supplemental therapy in preventing PHN.

\section{Methods}

\section{Eligibility Criteria}

\section{Studies}

We searched for all RCTs of analgesic methods used during the acute phase of $\mathrm{HZ}$ for preventing PHN.

\section{Participants}

Patients with $\mathrm{HZ}$ who were treated during the first 14 days were included in the study.

\section{Interventions}

We assessed supplemental therapies commonly used in clinical practice including systemic adjuncts (gabapentin, pregabalin, and amitriptyline) and interventional procedures (nerve block, epidural analgesics, and transcutaneous electric nerve stimulation). We did not include the trials that evaluated the efficacy of antiviral agents or corticosteroids in preventing PHN; these trials have been reviewed in other meta-analyses. Trials that evaluated the administration of acupuncture, ultraviolet $B$, hyperbaric oxygen, intravenous vitamin $C$, topical aspirin/diethyl ether mixture, adenosine monophosphate, or levodopa were also not included in our review because they are not commonly used in clinical practice. We included trials that compared supplemental therapies with current standard therapies but not with other treatments.

\section{Primary Outcomes}

The presence of PHN in 3 months after the acute rash presence.

\section{Secondary Outcomes}

1. The presence of PHN in 6 and 12 months after the acute rash presence.

2. The pain severity at one week, 3 weeks, and 3 months.

3. The quality of life at 3,6 , and 12 months after the acute rash presence.

4. Adverse events within the study period. We accessed both serious and nonserious adverse events in this analysis and reported them by 2 categories: systemic adjunct treatments relevant adverse events and interventional procedures relevant adverse events. Serious adverse events are those that resulted in death, produced or aggravated disability, threatened the safety of life, or required/ prolonged hospitalization.

\section{Search Strategy}

We searched for all RCTs of analgesic methods for preventing PHN and limited the language of publication to English.

We searched CENTRAL (1976 to March 2016), MEDLINE (1977 to January 2016), and EMBASE (May 1980 to December 2016) databases for RCTs. The following search terms were used in combination: "herpes zoster," "zona," "zoster," "shingles," "zoster-associated pain," "herpetic pain," "herpetic heuralgia," "postherpetic neuralgia," "PHN," "gabapentin," "pregabalin," "amitriptyline," "stellate ganglion," "nerve block," "anesthesia, local," "injections, epidural," "transcutaneous electric nerve stimulation," and "paravertebral."

\section{Study Selection}

The potentially eligible studies were evaluated by 2 independent reviewers according to the inclusion and exclusion criteria. After excluding the duplicate records, the remaining articles were scrutinized based on their titles and abstracts. Then, the full texts of the articles were obtained, and the 2 initial reviewers read them independently. Any disagreement was resolved by discussion or with the help of a third person, if needed.

\section{Quality Assessment}

Two reviewers assessed the risk of bias in each trial independently according to the Cochrane Collaboration standard scheme, which includes 7 criteria: random sequence generation, allocation concealment, blinding of participants and personnel, blinding of outcome assessment, incomplete outcome data, selective outcome reporting, and any other potential sources of bias. All 
of the included trials were judged for each item as high risk, low risk, or unclear risk.

\section{Statistical Analysis}

The data of participants, interventions, and outcomes were extracted by 2 independent review authors and entered into RevMan 5.3 (The Nordic Cochrane Centre for The Cochrane Collaboration, Copenhagen, Denmark). The results of dichotomous outcomes were expressed as risk ratios (RRs), while continuous outcomes were expressed as means and calculated mean differences (MDs), all with 95\% confidence intervals (Cls).

We evaluated heterogeneity among each analysis using the chi-square test with a $10 \%$ level of statistical significance $(P<0.1)$ and $I^{2}>50 \%(35,36)$. If statistical heterogeneity was not absent, a fixed-effect model was used. When a significant heterogeneity was present, we used a random-effects model and performed a subgroup analysis and a sensitivity analysis to help identify the possible reasons for heterogeneity. The subgroup analysis was performed according to clinical and methodological heterogeneity (including study design and interventional characteristics) (36).

The sensitivity analysis was undertaken by rerun-

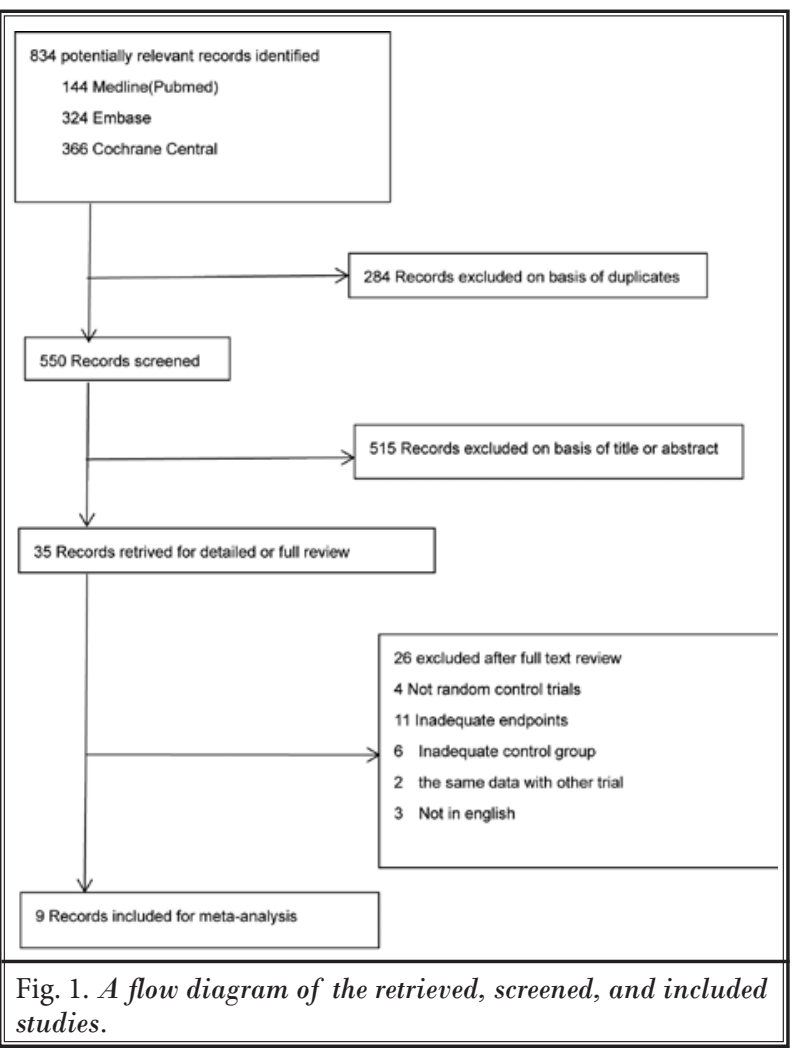

ning the meta-analysis after omitting the trials that had a high risk of bias. For trials that provided insufficient information to pool, we performed a descriptive analysis.

\section{Results}

\section{Study Selection}

We identified 834 records in the electronic databases: 145 in MEDLINE, 323 in EMBASE, and 366 in CENTRAL. After screening the titles and abstracts, 35 studies remained. After reviewing the full texts, only 9 trials were included in our analysis (Ahmed et al, 1998; Bowsher et al, 1997; Ji et al, 2009; Krcevski Skvarc et al, 2010; Lee et al, 2016; Makharita et al, 2012; Makharita et al, 2015; Pasqualucci et al, 2000; Van et al, 2006) (31-34,3741) (Fig. 1). Of 26 trials that were excluded, 6 trials did not compare the experimental group with the placebo or the current standard treatment (antivirals and analgesics as needed). Four trials were not RCTs and 11 trials did not include the primary outcome: the incidence of PHN (persistent pain 90 days after the acute rash presence). Three trials were not in English and 2 trials used the same data reported in the study done by Van et al (34). The details of the characteristics of the excluded studies are shown in Table S1 (supplementary material).

\section{Study Characteristics}

A total of 1,757 participants received treatment (888 in the experimental group and 867 in the control group), with 739 of them being men and 1,018 being women. Among them, 7 trials included participants older than 50 years; 2 trials did not limit the age of participants. Further, 5 trials included participants with different degrees of pain, 3 trials included participants with moderate to severe pain at presentation, and only one trial included participants with severe pain. Among the 9 trials, 3 trials compared supplemental systemic adjunct treatments (tricyclic antidepressants or anticonvulsants) to the standard therapy, and 6 trials compared interventional procedures to the standard therapy. All of the trials followed the participants for at least 3 months, and 2 of the trials monitored the participants for one year. Table 1 shows the basic characteristics of the included studies.

\section{Risk of Bias in Included Studies}

Figures 2 and 3 show the risk of bias assessments among each study based on the Cochrane Handbook 5.1.0. The results show that all of the trials were ran- 


\begin{tabular}{|c|c|c|c|c|c|c|c|}
\hline & 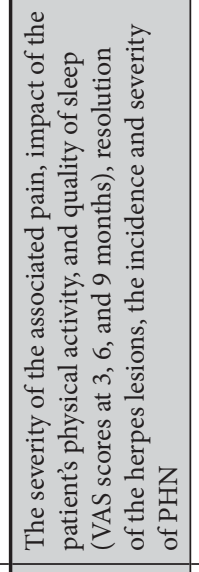 & 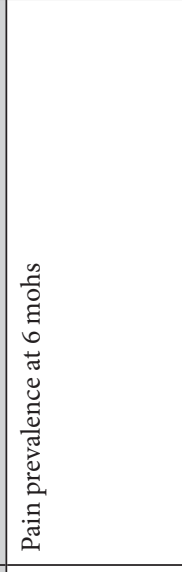 & 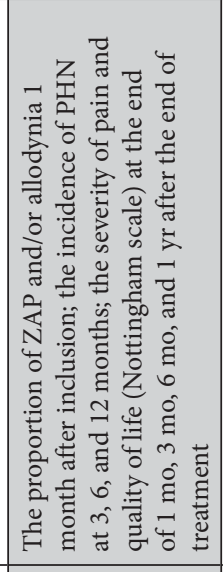 & 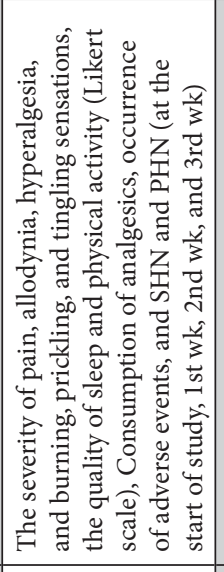 & 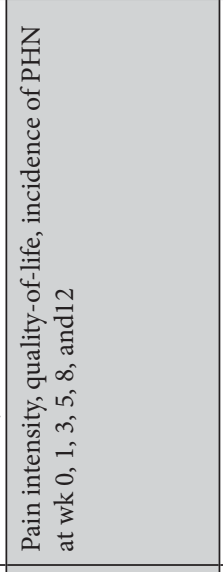 & 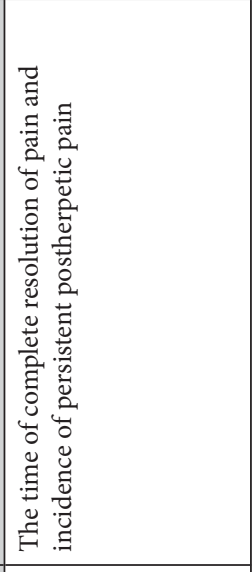 & 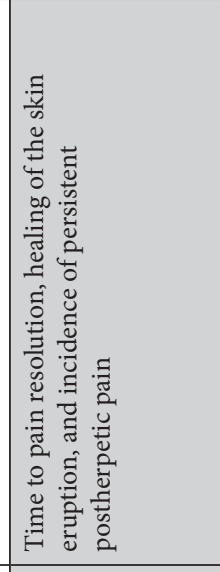 \\
\hline 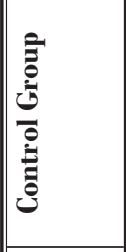 & 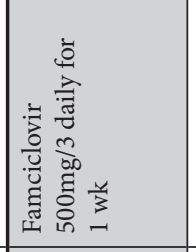 & 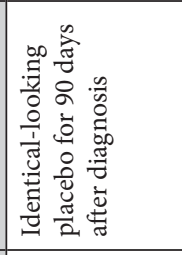 & 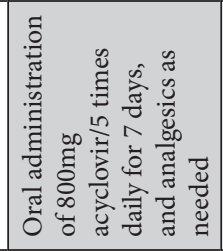 & 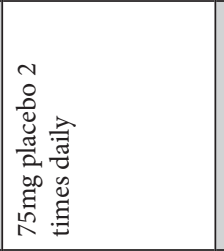 & 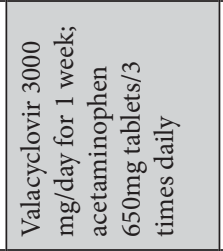 & 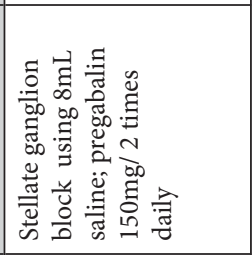 & 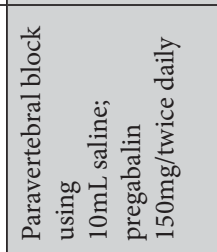 \\
\hline 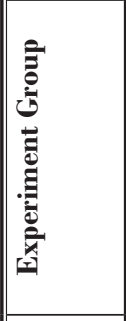 & 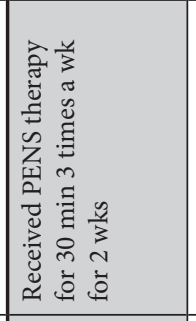 & 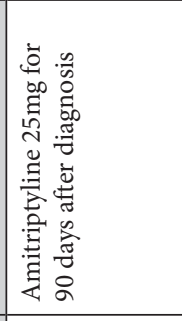 & 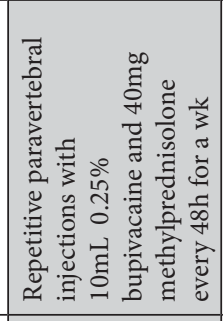 & 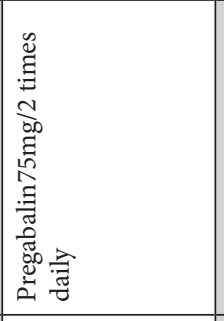 & 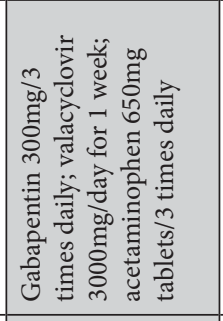 & 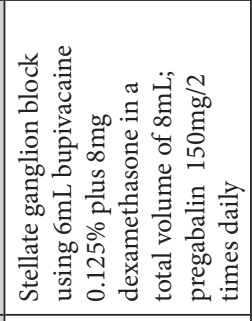 & 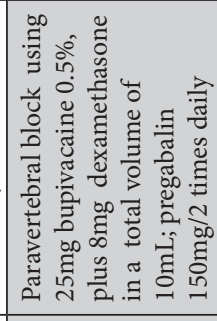 \\
\hline 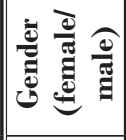 & 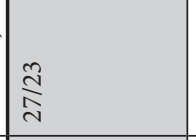 & 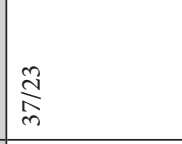 & \begin{tabular}{|l}
$\infty$ \\
$\stackrel{\infty}{2}$ \\
\multirow{2}{*}{}
\end{tabular} & $\stackrel{9}{2}$ & $\frac{m}{i}$ & $\frac{\hat{N}}{\stackrel{N}{m}}$ & $\frac{i}{\infty}$ \\
\hline 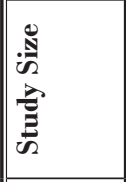 & 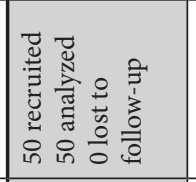 & 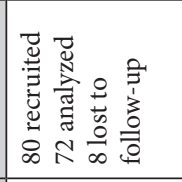 & 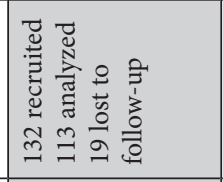 & 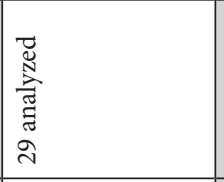 & 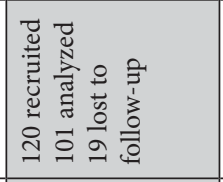 & 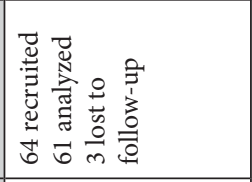 & 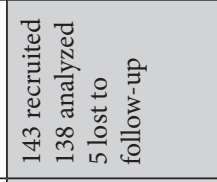 \\
\hline 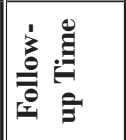 & $\begin{array}{l}\text { o } \\
\text { ఏ్ } \\
\text { a }\end{array}$ & 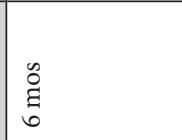 & 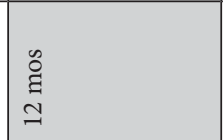 & $\begin{array}{l}\infty \\
\stackrel{0}{a} \\
\tilde{n}\end{array}$ & $\begin{array}{l}\infty \\
\text { ڤ్ } \\
m\end{array}$ & $\begin{array}{l}\text { o } \\
\text { gु }\end{array}$ & 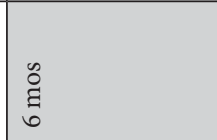 \\
\hline & 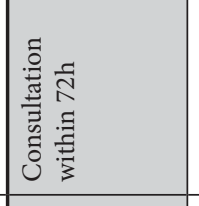 & 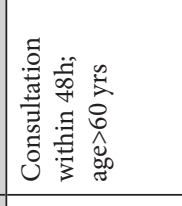 & 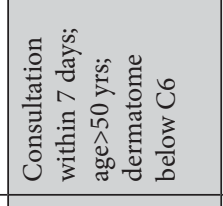 & 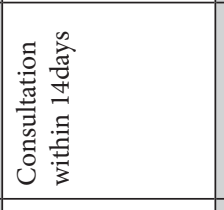 & 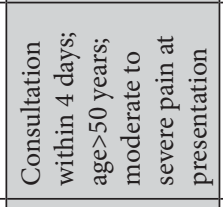 & 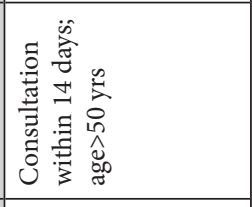 & 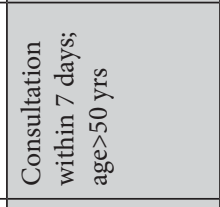 \\
\hline 量 & 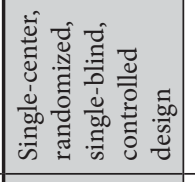 & 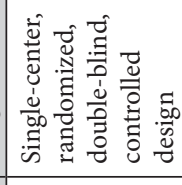 & 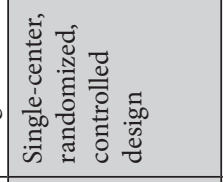 & 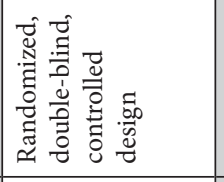 & 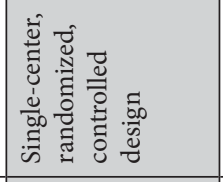 & 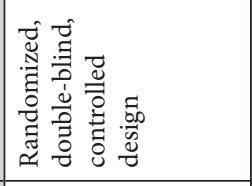 & 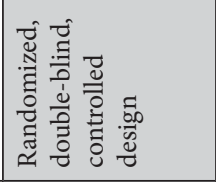 \\
\hline 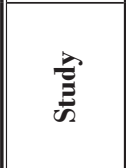 & 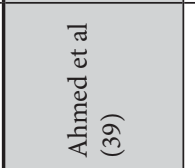 & 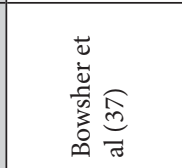 & 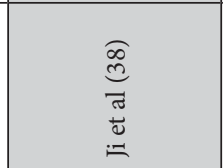 & 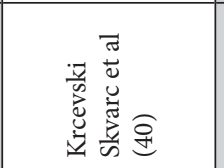 & 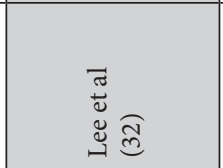 & 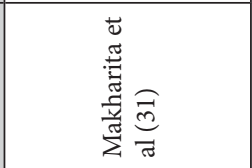 & 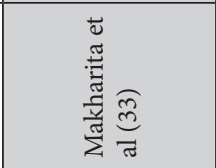 \\
\hline
\end{tabular}




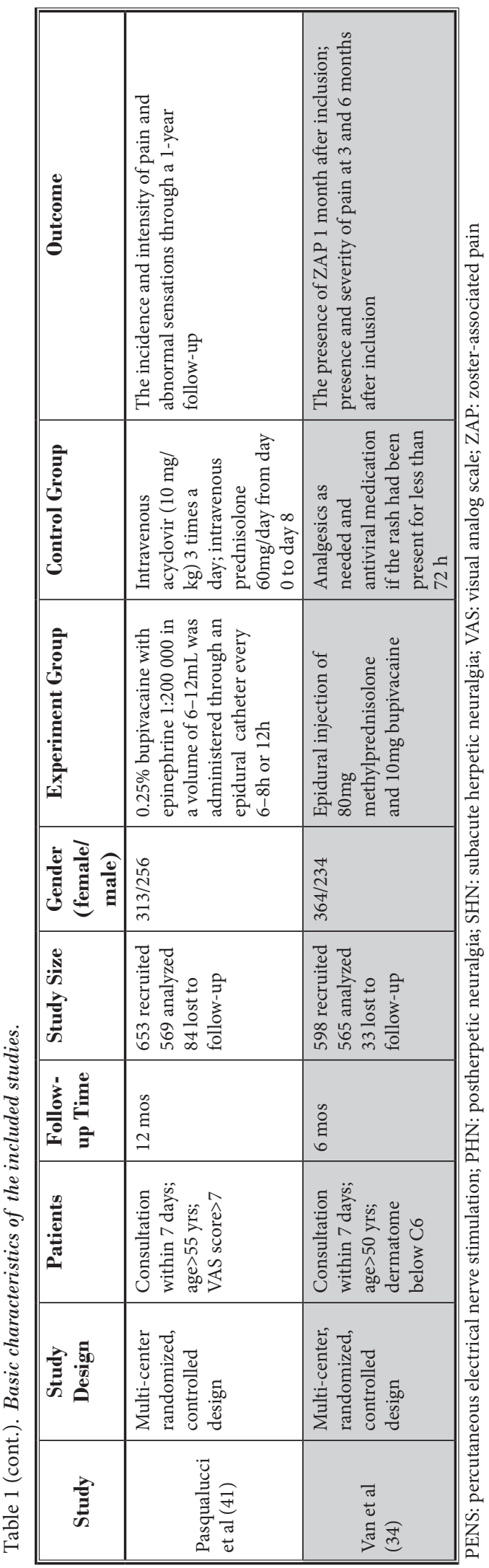

domized design, but half of them did not report the methods of random sequence generation. Allocation concealment and double-blinding were not reported in most of the trials. The details of the risk of bias are shown in Table S2.

\section{Meta-analysis Results}

\section{Primary Outcome Measure}

Nine trials with a total of 1,662 participants reported the incidence of PHN in 3 months after the acute rash presence. The results show that supplemental therapy during the acute phase of $\mathrm{HZ}$ prevents PHN in 3 months after the onset of the rash (RR $0.53,95 \% \mathrm{Cl} 0.34$ to $0.81, P=0.004$ ) (Fig. 4).

\section{Secondary Outcome Measures}

\section{The presence of PHN in 6 and 12 months after the acute rash presence:}

Six trials reported the incidence of PHN in 6 months after the acute rash presence. We pooled the above relevant data in a meta-analysis, with a total of 1,385 participants, and the results indicate that treatment with supplemental therapies at the early stage of $\mathrm{HZ}$ can reduce the long-term prevalence of PHN (RR $0.43,95 \% \mathrm{Cl} 0.23$ to $0.78, P=0.006$ ) (Fig. 5). Only 2 trials, with a total of 598 participants, evaluated the development of PHN in 12 months after the acute rash presence; the results show that supplemental local anesthesia significantly reduced the presence of PHN after 12 months (RR $0.17,95 \% \mathrm{Cl}$ 0.10 to $0.28, P<0.0001$ ) (Fig. 6).

\section{Pain severity at one week, 3 weeks, and 3 months:}

Eight studies evaluated the pain severity after treating with supplemental therapies. Seven of these 8 trials reported the changes of pain severity at 3 weeks, but the pain scale was presented in different methods (mean \pm SD in 2 studies, mean in one study, median+range in 3 studies, and median + inter - quartile range in one study); as a result, we were unable to pool the data in a meta-analysis, thus we made a descriptive analysis as follows.

All of the 8 studies showed that the visual analog scale (VAS) values significantly decreased at each follow-up timepoint when compared to the basic value in every group, but the difference of pain intensity between the experimental group and the control group were not consistent. Five of them showed that the decrease of pain scores had similar slopes in both of the groups. One study showed that the score was significantly lower in the paravertebral injection group at the third week $(P$ $<0.001$ ), but later ( 4 weeks, 12 weeks, and 24 weeks) there was no difference. Another study showed that pain resolved more rapidly in patients treated with stellate ganglion blockade $(P<$ 0.05) at both the short-term and long-term assessments. 
Supplemental Therapy on Preventing Postherpetic Neuralgia

Random sequence generation (selection bias)

Allocation concealment (selection bias)

Blinding of participants and personnel (performance bias)

Blinding of outcome assessment (detection bias)

Incomplete outcome data (attrition bias)

Selective reporting (reporting bias)

Other bias
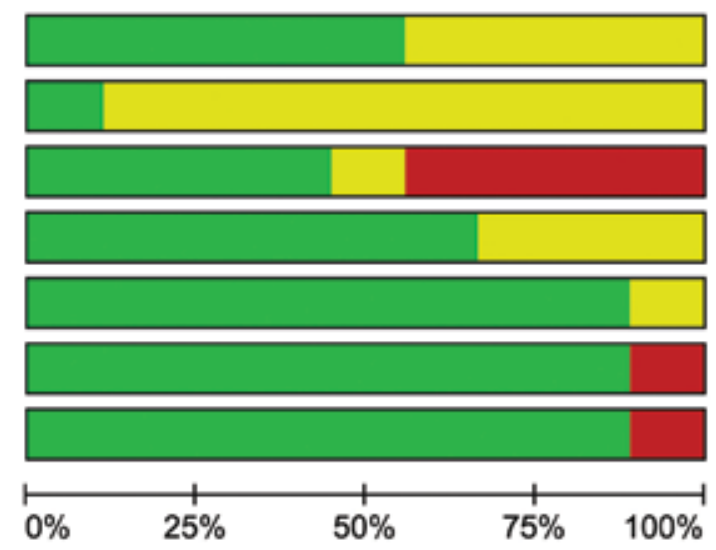

Low risk of bias

Unclear risk of bias

High risk of bias

Fig. 2. Risk of bias graph: the review authors' judgments about each risk of bias item presented as percentages across all of the included studies.

Quality of life after 3, 6, and 12 months:

Only one trial evaluated the quality of life, measured with the Nottingham scale, after 3, 6, and 12 months. The Nottingham scale decreased in both the paravertebral group and the standard group, that is to say in both of the groups the quality of life improved, but the difference between the groups was not significant at each assessment time $(P=0.921)$.

\section{Adverse events during the study periods:}

Both serious and nonserious adverse events were evaluated in these trials.

\section{Serious Adverse Events}

No serious adverse events were reported in any of the trials during the study period.

\section{Nonserious Adverse Events}

Seven included trials reported details of nonserious adverse events; another 2 trials did not mention relative adverse events in their researches. We reported these adverse events by 2 categories: systemic adjunct treatments relelvant adverse events and interventional procedures relevant adverse events. Systemic treatments were more likely to result in gastrointestinal symptoms, dizziness, or headache, while injection-relevant complications such as hypotension, bradycardia, change in voice, dysphagia, drowsiness, or headache were more concerned about for interventional treatments.

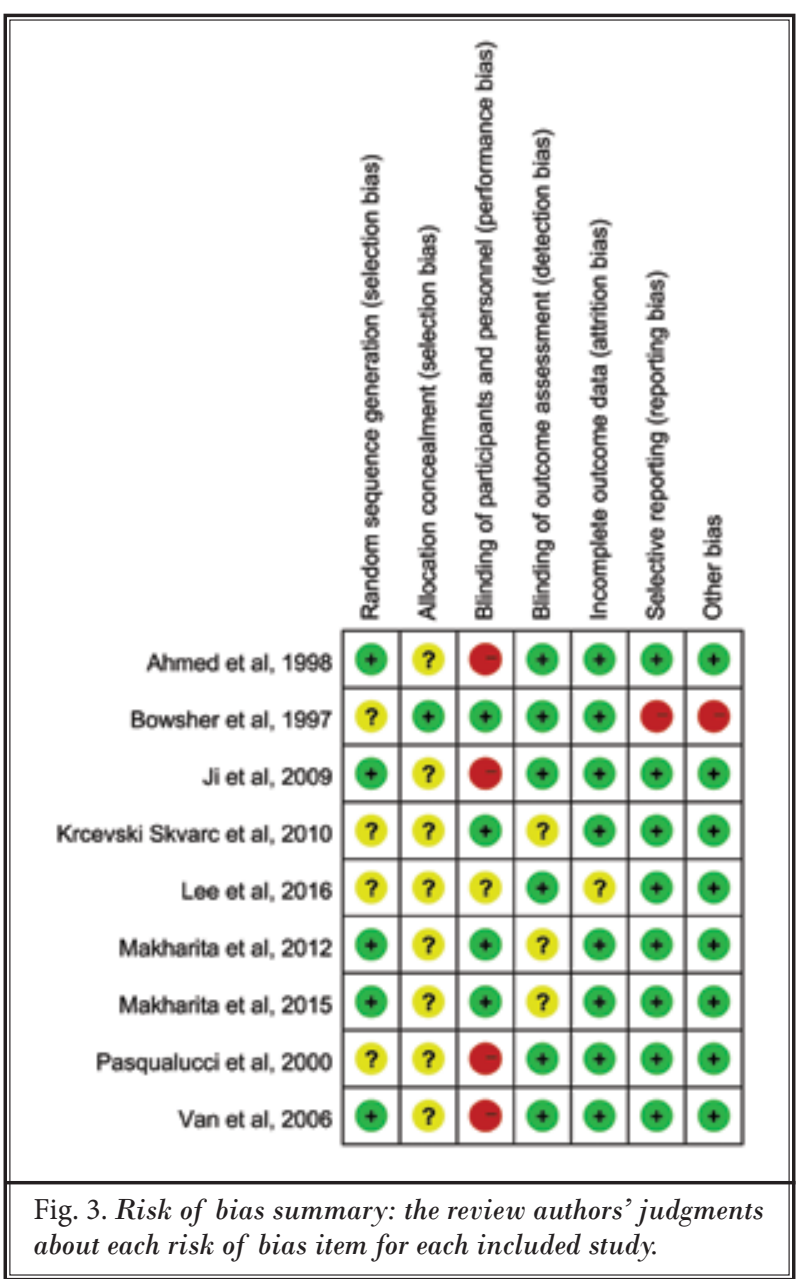




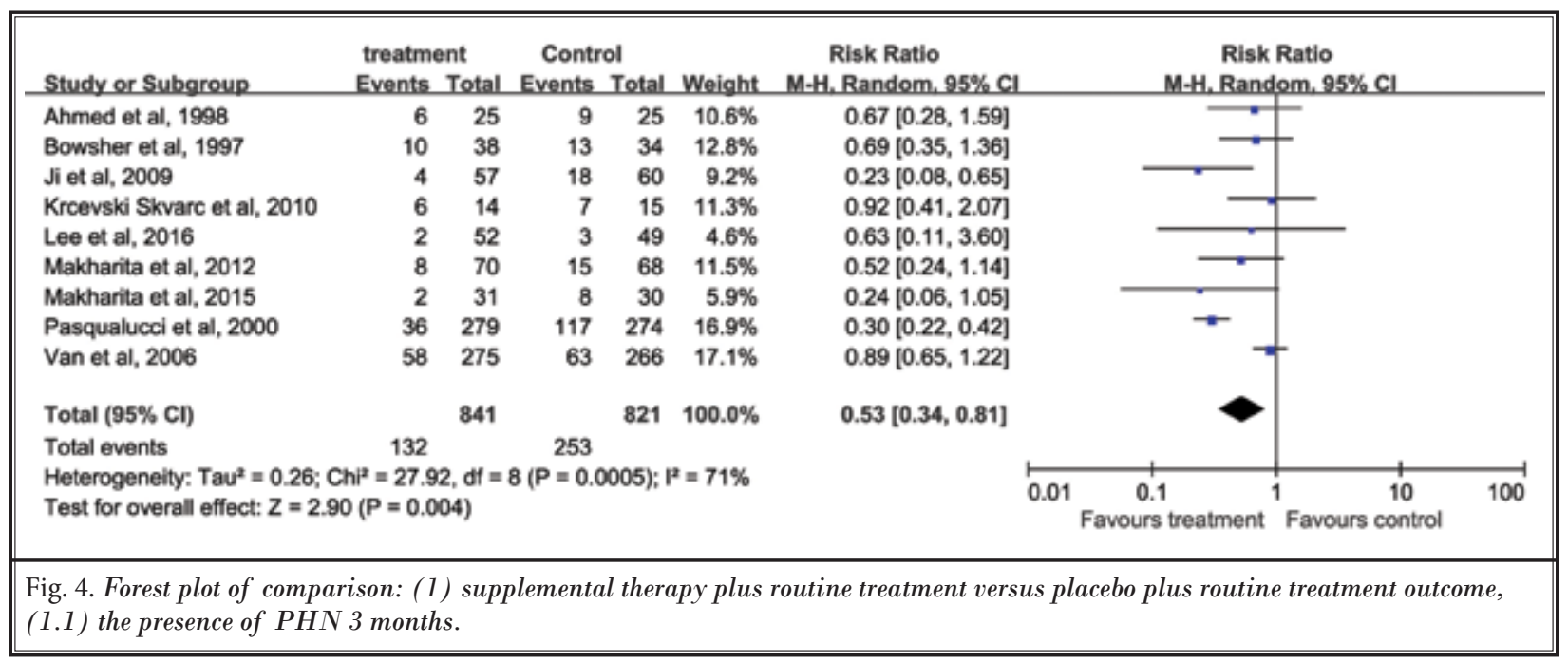

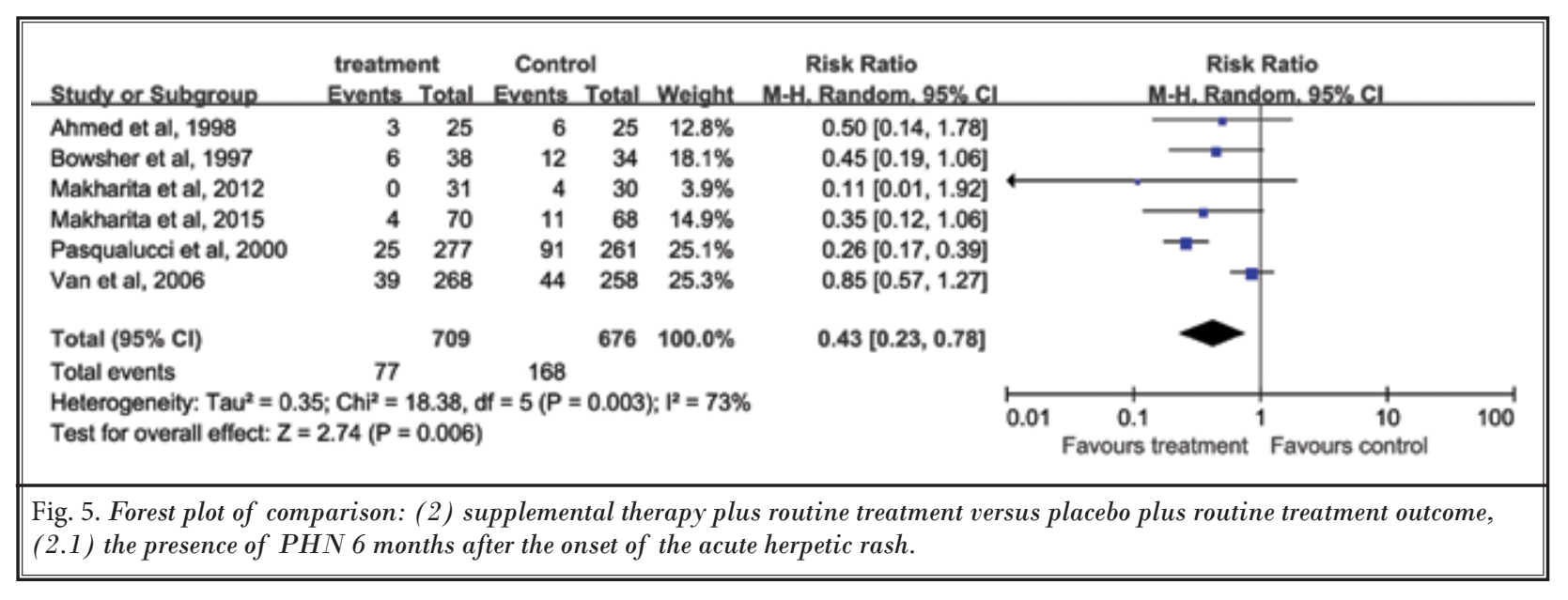

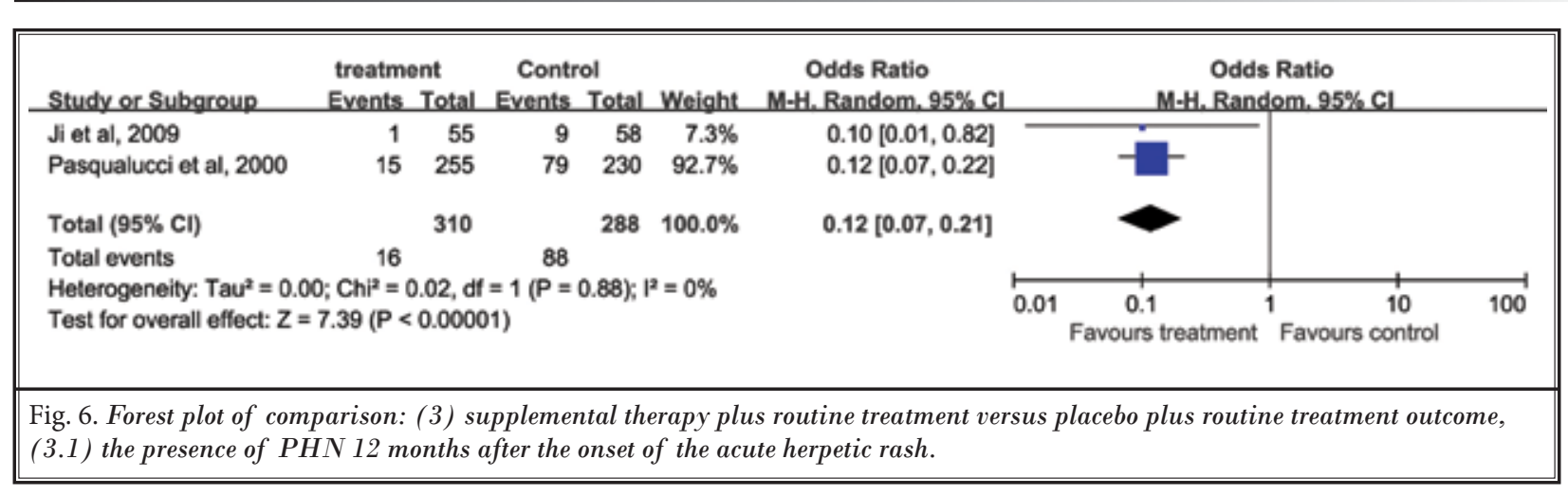

\section{Systemic Adjunct Treatments Relevant Adverse Events}

Two of the 3 trials performing systemic adjunct treatments reported relevant adverse events. Lee et al (32) reported that the most common adverse events in the gabapentin group were dizziness (15.4\%), dyspepsia $(13.5 \%)$, and nausea $(13.5 \%)$, and in the control group the most common adverse events were dyspepsia $(12.2 \%)$ and nausea (10.2\%). Krcevski Skvarc et al (40) reported that the most common adverse event was dry 
Supplemental Therapy on Preventing Postherpetic Neuralgia

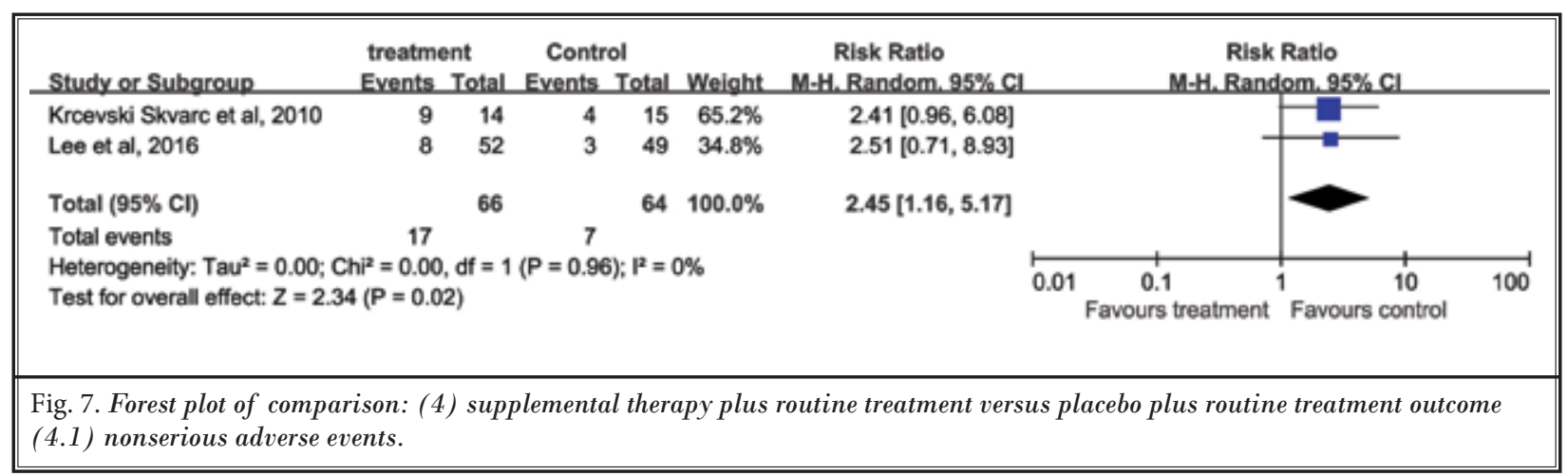

mouth $(65.5 \%)$ in their research, and a higher overall incidence of adverse events was seen in the pregabalin group than in the placebo group ( $52 \%$ vs. $36 \%$, respectively). Eight patients withdrew from the trial because of adverse events ( 5 from the pregabalin group and 3 from the placebo group).

As one patient may have more than one symptom, the overall incidence of adverse events in each group was not available in all of the studies. We conducted a meta-analysis of the most common side effect: dizziness. The results show that the patients in the systemic treatment groups suffered more dizziness than the patients in the placebo group ( $R R 2.45,95 \% \mathrm{Cl} 1.16$ to 5.17) (Fig. 7).

\section{Interventional Procedures Relevant Adverse Events}

Five of the included trials reported adverse events related to interventional procedures. However, because most of the adverse events were procedure-related and different procedures have different relevant adverse events, a meta-analysis was not available; therefore, we made a descriptive analysis as follows. Compared to patients who received standard therapy or placebo treatment, patients who received a single paravertebral injection had a higher risk of suffering hypotension, bradycardia, and vasovagal attack. Stellate ganglion blockade was more likely to result in voice change and dysphagia. Patients were more likely to have their epidural catheter come out and suffer from perforation of the dura mater after epidural catheterization and more likely to suffer from dizziness, flushness, headache, and backache after epidural injection.

Only 13 patients who received epidural catheterization in the study done by Pasqualucci et al (41) failed to complete therapy due to the adverse events. Of the
13 patients, 3 of them suffered from frequent sweating, fainting spells, neck pain or stiffness, one of them had paresis of the left leg and oliguria, and the remaining 9 patients' epidural catheter came out. All of these adverse effects resolved completely.

\section{Subgroup Analysis: Different Categories of Treatments}

\section{Primary Outcomes:}

\section{Systemic Adjunct Treatments:}

The subgroup meta-analysis of 3 trials that compared supplemental systemic adjunct therapy to placebo, with a total of 202 participants, shows that supplemental tricyclic anti-depressants (e.g., amitriptyline) or anti-epileptic drugs (e.g., gabapentin, pregabalin) did not play an important role in preventing the occurrence of PHN in 3 months after inclusion (RR $0.76,95 \% \mathrm{Cl} 0.46$ to $1.26, P=0.29$ ) (Fig. 8).

\section{Interventional Procedures:}

The subgroup meta-analysis of 6 trials that compared supplemental interventional procedures with placebo, with a total of 1,460 participants, shows that interventional procedures prevented the occurrence of $\mathrm{PHN}$ in 3 months after inclusion (RR $0.45,95 \% \mathrm{Cl} 0.26$ to 0.80, $P=0.0001$ ) (Fig. 8).

\section{Secondary Outcomes:}

\section{Systemic Adjunct Treatments:}

Only one trial with 72 participants in this subgroup reported the incidence of PHN in 6 months after the acute rash presence. Although the result showed that the early treatment of older patients with acute $\mathrm{HZ}$ by 


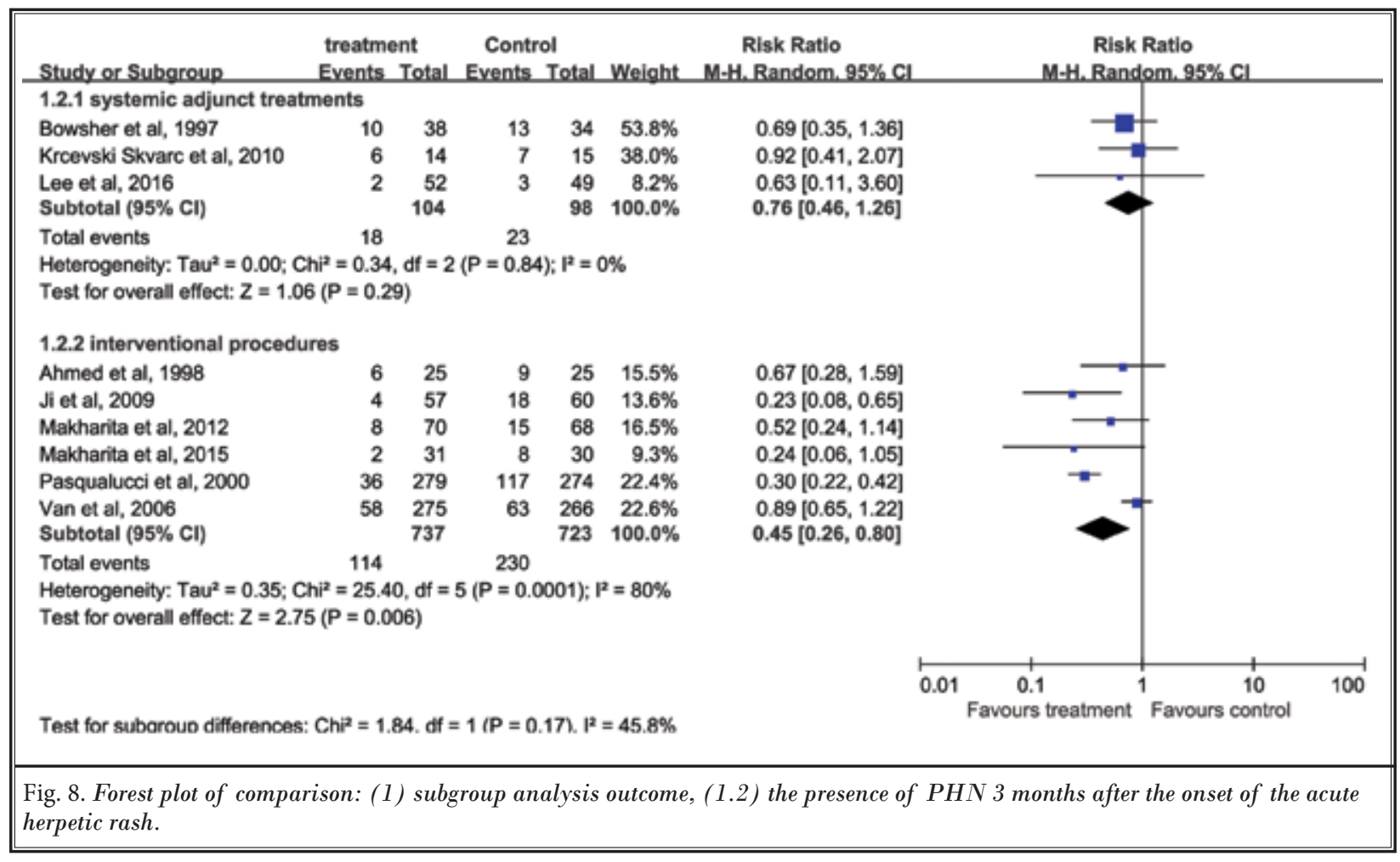

low-dose amitriptyline (25 nag) can prevent PHN after 6 months, $15.8 \%$ of the patients still reported pain in the amitriptyline group and $35.3 \%$ still reported pain in the control group. However, the beneficial effect was not seen in the meta-analysis (RR $0.45,95 \% \mathrm{Cl} 0.19$ to 1.06 , $P=0.07$ ) (Fig. 9).

\section{Interventional Procedures:}

Five included trials, with 1,313 participants, reported the development of PHN in 6 months after the acute rash presence. The results show that the early treatment of patients with nerve block or percutaneous electrical nerve stimulation (PENS) at the acute phase of shingles can prevent the prevalence of PHN at 6 months (RR $0.41,95 \% \mathrm{Cl} 0.20$ to $0.87, P=0.02$ ) (Fig. 9).

\section{Sensitivity Analysis}

Significant heterogeneity $\left(I^{2}>50 \%\right)$ was present both in the primary outcome analysis and the secondary outcome analysis, therefore we used a randomeffects model in these meta-analyses. After performing subgroup analyses, there was still significant heterogeneity in the primary and secondary outcome analyses in the interventional procedures subgroup ( $I^{2}$
$=80 \%$ and $\mathrm{I}^{2}=78 \%$, respectively). To identify the possible reasons for heterogeneity, we made a sensitivity analysis by omitting all of the 9 trials one-by-one and repeating the calculation with the remaining trials. The results show that the study done by Pasqualucci et al (41) had high heterogeneity (when omitting this study the 12 changed from about $70 \%$ to about $30 \%$, while omitting the other trials the $\mathrm{I}^{2}$ almost had no change). The possible reason for this is that the study done by Pasqualucci et al (41) involved patients with a serious presentation of pain, which is known as one of the risk factors of PHN, while the other trials involved patients with moderate to severe pain or had no limitation.

After omitting the study with high heterogeneity, the primary outcome that supplemental therapies used at the early stage prevented the development of PHN in 3 months after inclusion did not change (RR 0.65 , $95 \% \mathrm{Cl} 0.47$ to 0.90 in overall analysis; RR $0.53,95 \% \mathrm{Cl}$ 0.31 to 0.91 in interventional procedures subgroup analysis). The second outcome that the effect of the early use of supplemental therapies on preventing the occurrence of PHN in 6 months after inclusion was still significant in the overall analysis (RR $0.58,95 \% \mathrm{Cl} 0.36$ to 0.93 ), but changed from significant (RR $0.83,95 \% \mathrm{Cl}$ 
Supplemental Therapy on Preventing Postherpetic Neuralgia

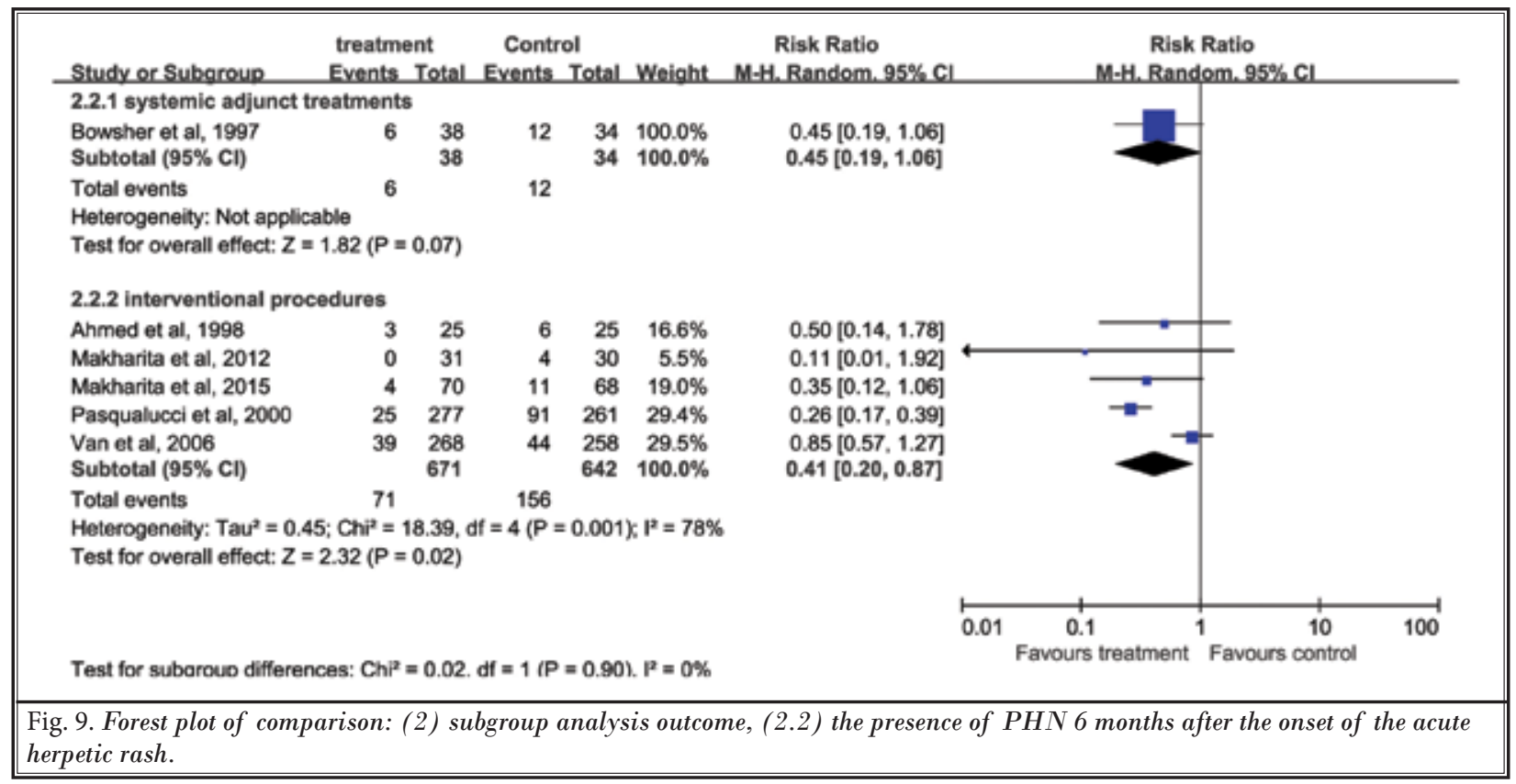

0.71 to $0.96, P=0.01$ ) to not significant (RR $0.99,95 \% \mathrm{Cl}$ 0.83 to $1.17, P=0.89$ ) in the interventional procedures subgroup analysis.

\section{Discussion}

Antiviral agents and analgesics are parts of the current standard therapy for acute $\mathrm{HZ}$ according to the 3-step WHO pain ladder guidelines. Although the standard therapy can accelerate the resolution of inflammation and tissue injury, reduction of the severity of symptoms associated with acute $\mathrm{HZ}$, and PHN severity and its duration, it does not reduce the incidence of PHN. Supplemental therapies such as tricyclic antidepressants, anticonvulsants, and local anesthetics are commonly used to relieve the acute pain and, at the same time, may reduce the incidence of PHN. Several relevant studies evaluated the efficacy of these supplemental treatments for preventing PHN. The differing results prompted us to conduct this systematic review of RCTs.

\section{Summary of Main Results}

We included 9 RCTs that evaluated relevant endpoints of $\mathrm{HZ}$ and PHN. From there, 3 of them compared tricyclic antidepressants or anticonvulsants therapy with the control group and the remaining 6 trials compared interventional procedures with the control group. The result is robust in that the early use of supplemental therapy can significantly prevent the development of
PHN in 3 and 6 months after the acute rash presence (the results of the overall analysis was consistent with that of the sensitive analysis). The evidence is moderate in that the early use of supplemental interventional procedures such as nerve block or epidural injection can significantly reduce the incidence of PHN. There is also moderate evidence that shows that the early use of supplemental systemic treatments has no significant effect on preventing PHN.

Moreover, the severity of pain, quality of life, and tolerability of adverse events can help evaluate the efficacy of these methods on preventing PHN. A significant decrease in VAS values was reported in all of the 9 trials when compared to the basic values, but the decrease slopes of the pain scores were similar between the experimental group and the control group in 5 of them. In the trial that assessed the quality of life 6 and 12 months after inclusion, the result indicated that the quality of life improved in both of the groups, but the difference between the groups did not reach statistical significance at each assessment time. Serious adverse events were not reported in any of the trials during the study period. Neurologic symptoms such as dizziness and gastrointestinal symptoms such as dyspepsia were more common in the gabapentin or pregabalin group than in the control group. Relevant adverse events such as hypotension, bradycardia, voice change, dysphagia, drowsiness, or headache during or after interventions were more common in the interventional procedures 
groups. Thirteen patients in the interventional procedures group failed to complete therapy due to the adverse events, but all of these events were nonserious and improved immediately or several days after symptomatic supportive treatments.

\section{Agreements and Disagreements}

There has been only one systematic review and one meta-analysis that identified the effect of the treatment of acute $\mathrm{HZ}$ on preventing PHN, and most of the trials assessed in those analyses were included in our review.

Alper et al (42) published an overview of clinical trials to determine if any treatment towards acute $\mathrm{HZ}$ alters the occurrence of PHN. The treatments reviewed in that analysis included oral acyclovir, famciclovir, valacyclovir, steroids, oral amitriptyline, and PENS. The results show that the evidence that current interventions (especially oral antiviral agents and the use of steroids) prevent or shorten PHN was limited, but amitriptyline and PENS is promising on preventing PHN, though the evidence was insufficient. However, the result of our meta-analysis shows that oral amitriptyline, gabapentin, or pregabalin has no significant effect on preventing PHN. Considering the heterogeneity of different drugs and the small number of trials, the evidence was limited as well. Well-designed and larger trials of the effect of amitriptyline and gabapentin on preventing PHN should be conducted in the future.

Jang and colleagues (43) performed a meta-analysis to evaluate if interventional pain management procedures during the acute phase of $\mathrm{HZ}$ could prevent PHN in the elderly. It involved the same 5 trials included in our interventional procedures subgroup, but the latest trial was not included. The results are consistent with ours in that the early use of interventional procedures can prevent PHN in 3 months after acute rash presence in elderly patients. However, the meta-analysis did not assess the results of the quality of life and adverse events, which play a significant supporting role in evaluating the usefulness of interventional procedures.

\section{Limitations}

Firstly, there were only a few RCTs published, and most of the RCTs lacked adequate allocation concealment or blinding. Secondly, we limited the language to English, which may have led to the omission of publications that were published in non-English journals. Thirdly, we did not create a funnel plot due to the small number of studies, which may limit the value of the identification of publication bias. Moreover, some of the data was insufficient and unable to be pooled in a meta-analysis, such as the quality of life (the patientoriented outcome) which was absent in almost $90 \%$ of the trials. Finally, our study was limited to patients who had normal immune functions and who had received standard antiviral agents as needed; therefore, the effect of the early use of supplemental therapy in patients who did not receive antiviral therapy and in patients with immune disorders is unknown.

\section{Conclusion}

This meta-analysis demonstrates that the early use of supplemental therapies can significantly reduce the incidence of PHN. The subgroup analysis shows that supplemental interventional procedure is beneficial on preventing PHN, while supplemental systemic adjunct treatment is not. The early use of interventional procedures for acute pain may be the preferred choice for patients without contraindication, but the evidence for both is moderate. Further studies of high-quality RCTs are required. 


\section{Supplemental Therapy on Preventing Postherpetic Neuralgia}

Table S1. The characteristics of the excluded studies [ordered by study ID].

\begin{tabular}{|c|c|c|c|}
\hline Study & \multicolumn{3}{|c|}{ Reason for Exclusion } \\
\hline $\begin{array}{l}\text { Balakrishnan et al, } 2001 \\
\text { (44) }\end{array}$ & \multicolumn{3}{|c|}{ RCT, but the control group was treated with oral aspirin } \\
\hline Bareggi et al, 1998 (50) & \multicolumn{3}{|c|}{$\begin{array}{l}\text { Confirmed not a true RCT } \\
\text { The control group was treated with oral aspirin. } \\
\text { The outcomes did not include the incidence of PHN. }\end{array}$} \\
\hline Bruni et al, 1984 (45) & \multicolumn{3}{|c|}{$\begin{array}{l}\text { The control group was treated with intramuscular neuramide. } \\
\text { The outcomes did not include the incidence of PHN. }\end{array}$} \\
\hline Castelli et al, 1986 (54) & \multicolumn{3}{|c|}{ The outcomes did not include the incidence of PHN. } \\
\hline Dworkin et al, 2009 (55) & \multicolumn{3}{|c|}{$\begin{array}{l}\text { The observation period was only } 28 \text { days. } \\
\text { The outcomes did not include the incidence of PHN. }\end{array}$} \\
\hline Fujii et al, 2010 (65) & \multicolumn{3}{|c|}{ The study was not in English. } \\
\hline Guo et al, 2007 (66) & \multicolumn{3}{|c|}{ The study was not in English. } \\
\hline Harding et al, 1986 (56) & \multicolumn{3}{|c|}{ The outcomes did not include the incidence of PHN. } \\
\hline Higa et al, 1998 (57) & \multicolumn{3}{|c|}{$\begin{array}{l}\text { The observation period was only } 60 \text { min. } \\
\text { The outcomes did not include the incidence of PHN. }\end{array}$} \\
\hline Hwang et al, 1999 (51) & \multicolumn{3}{|c|}{ Confirmed not a true RCT } \\
\hline Isbary et al, 2014 (58) & \multicolumn{3}{|c|}{ The outcomes did not include the incidence of PHN. } \\
\hline $\begin{array}{l}\text { Jensen-Dahm et al, } 2011 \\
\text { (59) }\end{array}$ & \multicolumn{3}{|c|}{$\begin{array}{l}\text { The observation period was only } 6 \mathrm{~h} \text {. } \\
\text { The outcomes did not include the incidence of PHN. }\end{array}$} \\
\hline Kanodia et al, $2011(60)$ & \multicolumn{3}{|c|}{$\begin{array}{l}\text { The observation period was only } 4 \text { wks. } \\
\text { The outcomes did not include the incidence of PHN. }\end{array}$} \\
\hline Kanodia et al, 2012 (61) & \multicolumn{3}{|c|}{$\begin{array}{l}\text { The observation period was only } 1 \text { mo. } \\
\text { The outcomes did not include the incidence of PHN. }\end{array}$} \\
\hline Liang et al, 2015 (46) & \multicolumn{3}{|c|}{ RCT, but the control group was treated with oxycodone } \\
\hline Lin et al, 2008 (62) & \multicolumn{3}{|c|}{$\begin{array}{l}\text { The observation period was only } 4 \text { wks. } \\
\text { The outcomes did not include the incidence of PHN. }\end{array}$} \\
\hline Manabe et al, 2004 (47) & \multicolumn{3}{|c|}{ RCT, but the control group was treated with intermittent epidural boluses } \\
\hline Opstelten et al, 2004 (68) & \multicolumn{3}{|c|}{ The same data as the Van et al, 2006 study (34) } \\
\hline Opstelten et al, 2006 (69) & \multicolumn{3}{|c|}{ The same data as the Van et al, 2006 study (34) } \\
\hline Siedler et al, 1999 (67) & \multicolumn{3}{|c|}{ The study was not in English. } \\
\hline Song et al, $2002(52)$ & \multicolumn{3}{|c|}{ Confirmed not a true RCT } \\
\hline Stepanoviæ et al, 2015 (63) & \multicolumn{3}{|c|}{ The outcomes did not include the exact incidence of PHN. } \\
\hline Tenicela et al, 1985 (64) & \multicolumn{3}{|c|}{ The outcomes did not include the incidence of PHN. } \\
\hline Wang $2002(53)$ & \multicolumn{3}{|c|}{ Confirmed not a true RCT } \\
\hline Xu et al, 2014 (48) & \multicolumn{3}{|c|}{$\begin{array}{l}\text { RCT, but the control group was treated with locally injected lidocaine } \\
\text { The outcomes did not included the incidence of PHN. }\end{array}$} \\
\hline $\mathrm{X}$ et al, $2016(49)$ & \multicolumn{3}{|c|}{ RCT, but the control group was treated with intramuscular methylcobalamin in addition to local lidocaine injection } \\
\hline \multicolumn{4}{|c|}{ Table S2. The risk of bias in each included study. } \\
\hline \multicolumn{2}{|l|}{ Bias } & Authors' Judgment & Support for Judgment \\
\hline Random sequence generati & (selection bias) & Low risk & A computer-generated randomization code was used. \\
\hline $\begin{array}{l}\text { Allocation concealment } \\
\text { (selection bias) }\end{array}$ & & Unclear risk & The method of allocation concealment was not described. \\
\hline $\begin{array}{l}\text { Blinding of participants an } \\
\text { (performance bias) }\end{array}$ & personnel & High risk & $\begin{array}{l}\text { Double-blind was unavailable because it does not mimic the sensation } \\
\text { provided by the electrical stimulation associated with PENS therapy. }\end{array}$ \\
\hline $\begin{array}{l}\text { Blinding of outcome assess } \\
\text { bias) }\end{array}$ & ent (detection & Low risk & The assessment was performed by a blind observer. \\
\hline Incomplete outcome data ( & trition bias) & Low risk & There were no pts lost to follow-up. \\
\hline Selective reporting (reporti & bias) & Low risk & The outcomes listed in the methods section were all reported. \\
\hline Other bias & & Low risk & No other potential bias was found. \\
\hline
\end{tabular}




\section{References}

1. Johnson RW, Rice AS. Clinical practice. Postherpetic neuralgia. N Engl J Med 2014; 371:1526-1533.

2. Grose C. Variation on a theme by Fenner: The pathogenesis of chickenpox. Pediatrics 1981; 68:735-737.

3. Ku C-C, Besser J, Abendroth A, Grose C, Arvin AM. Varicella-Zoster virus pathogenesis and immunobiology: New concepts emerging from investigations with the SCIDhu mouse model. J Virol 2005; 79:2651-2658.

4. Baron R, Tölle TR, Gockel U, Brosz M, Freynhagen R. A cross-sectional cohort survey in 2100 patients with painful diabetic neuropathy and postherpetic neuralgia: Differences in demographic data and sensory symptoms. Pain 2009; 146:34-40.

5. Johnson RW, Alvarez-Pasquin M-J, Bijl M, Franco E, Gaillat J, Clara JG, Labetoulle M, Michel J-P, Naldi L, Sanmarti LS, Weinke T. Herpes zoster epidemiology, management, and disease and economic burden in Europe: A multidisciplinary perspective. Ther Adv Vaccines 2015; 3:109-120.

6. Kawai K, Gebremeskel BG, Acosta C). Systematic review of incidence and complications of herpes zoster: Towards a global perspective. BMJ Open 2014; 4:e004833.

7. Johnson RW. Herpes zoster and postherpetic neuralgia. Optimal treatment. Drugs Aging 1997; 10:80-94.

8. Ragozzino MW, Melton LJ 3rd, Kurland LT, Chu CP, Perry HO. Population-based study of herpes zoster and its sequelae. Medicine (Baltimore) 1982; 61:310-316.

9. Helgason $S$, Petursson G, Gudmundsson S, Sigurdsson JA. Prevalence of postherpetic neuralgia after a first episode of herpes zoster: Prospective study with long term follow up. BM] 2000; 321:794-796.

10. Katz J, Cooper EM, Walther RR, Sweeney EW, Dworkin RH. Acute pain in herpes zoster and its impact on health-related quality of life. Clin Infect Dis 2004; 39:342-348.

11. Johnson RW, Bouhassira D, Kassianos G, Leplège A, Schmader KE, Weinke T. The impact of herpes zoster and postherpetic neuralgia on quality-of-life. BMC Med 2010; 8:37.

12. Mallick-Searle T, Snodgrass B, Brant JM. Postherpetic neuralgia: Epidemiology, pathophysiology, and pain management pharmacology. J Multidiscip
Healthc 2016; 9:447-454.

13. Coen PG, Scott F, Leedham-Green M, Nia T, Jamil A, Johnson RW, Breuer J. Predicting and preventing post-herpetic neuralgia: Are current risk factors useful in clinical practice? Eur J Pain 2006; 10:695-700.

14. Dworkin RH, Portenoy RK. Pain and its persistence in herpes zoster. Pain 1996; 67:241-251.

15. Jung BF, Johnson RW, Griffin DR, Dworkin $\mathrm{RH}$. Risk factors for postherpetic neuralgia in patients with herpes zoster. Neurology 2004; 62:1545-1551.

16. Bennett GJ. Hypotheses on the pathogenesis of herpes zoster-associated pain. Ann Neurol 1994; 35 Suppl:S38-S41.

17. Giovanni G, Nicoletta V, Parvanè K, Silvia $L$, Armando S. Prevention of herpes zoster and its complications: From the clinic to the real-life experience with the vaccine. J Med Microbiol 2016; 12:1363-1369.

18. Tyring S, Barbarash RA, Nahlik JE, Cunningham A, Marley J, Heng M, Jones T, Rea T, Boon R, Saltzman R. Famciclovir for the treatment of acute herpes zoster: Effects on acute disease and postherpetic neuralgia. A randomized, double-blind, placebo-controlled trial. Collaborative Famciclovir Herpes Zoster Study Group. Ann Intern Med 1995; 123:89-96.

19. Lilie HM, Wassilew $S$. The role of antivirals in the management of neuropathic pain in the older patient with herpes zoster. Drugs Aging 2003; 20:561-570.

20. Whitley RJ, Weiss H, Gnann JW Jr, Tyring S, Mertz GJ, Pappas PG, Schleupner C), Hayden F, Wolf J, Soong SJ. Acyclovir with and without prednisone for the treatment of herpes zoster. A randomized, placebo-controlled trial. The $\mathrm{Na}$ tional Institute of Allergy and Infectious Diseases Collaborative Antiviral Study Group. Ann Intern Med 1996; 125:376-383.

21. Han Y, Zhang J, Chen N, He L, Zhou M, Zhu C. Corticosteroids for preventing postherpetic neuralgia. Cochrane Database Syst Rev 2013; 3:CDoo5582.

22. Li Q, Chen N, Yang J, Zhou M, Zhou D, Zhang Q, He L. Antiviral treatment for preventing postherpetic neuralgia. Cochrane Database Syst Rev 2009; 2:CDoo6866.

23. Werner RN, Nikkels AF, Marinović B, Schäfer M, Czarnecka-Operacz M, Agius AM, Bata-Csörgő Z, Breuer J, Girolomoni G, Gross GE, Langan S, LapidGortzak R, Lesser TH, Pleyer U, Sellner J, Verjans GM, Wutzler P, Dressler C, Erd- mann R, Rosumeck S, Nast A. European consensus-based ( $\mathrm{S}_{2} \mathrm{k}$ ) Guideline on the Management of Herpes Zoster - guided by the European Dermatology Forum (EDF) in cooperation with the European Academy of Dermatology and Venereology (EADV), Part 2: Treatment. J Eur Acad Dermatol Venereol 2017; 31:20-29.

24. Woolf CJ. A new strategy for the treatment of inflammatory pain. Prevention or elimination of central sensitization. Drugs 1994; 47:1-9; discussion 46-47.

25. Kumar V, Krone K, Mathieu A. Neuraxial and sympathetic blocks in herpes zoster and postherpetic neuralgia: An appraisal of current evidence. Reg Anesth Pain Med 2004; 29:454-461.

26. Kotani $\mathrm{N}$, Kushikata $\mathrm{T}$, Hashimoto $\mathrm{H}$, Kimura F, Muraoka M, Yodono M, Asai M, Matsuki A. Intrathecal methylprednisolone for intractable postherpetic neuralgia. N Engl J Med 2000; 343:1514-1519.

27. Berry JD, Petersen KL. A single dose of gabapentin reduces acute pain and allodynia in patients with herpes zoster. Neurology 2005; 65:444-447.

28. Jensen-Dahm C, Rowbotham MC, Reda $H$, Petersen KL. Effect of a single dose of pregabalin on herpes zoster pain. Trials 2011; 12:55.

29. Dworkin RH, Barbano RL, Tyring SK, Betts RF, McDermott MP, PennellaVaughan J, Bennett GJ, Berber E, Gnann JW, Irvine C, Kamp C, Kieburtz K, Max MB, Schmader KE. A randomized, placebo-controlled trial of oxycodone and of gabapentin for acute pain in herpes zoster. Pain 2009; 142:209-217.

30. Migita T. Can early administration of pregabalin reduce the incidence of postherpetic neuralgia? Clin Exp Dermatol 2014; 39:755-756.

31. Makharita MY, Amr YM, El-Bayoumy Y. Effect of early stellate ganglion blockade for facial pain from acute herpes zoster and incidence of postherpetic neuralgia. Pain Physician 2012; 15:467-474.

32. Lee EG, Lee HJ, Hyun DJ, Min K, Kim $\mathrm{DH}$, Yoon MS. Efficacy of low dose gabapentin in acute herpes zoster for preventing postherpetic neuralgia: A prospective controlled study. Dermatol Ther 2016; 29:184-190.

33. Makharita MY, Amr YM, El-Bayoumy Y. Single paravertebral injection for acute thoracic herpes zoster: A randomized controlled trial. Pain Pract 2015; 15:229-235. 
34. Van Wijck AJ, Opstelten W, Moons KG van Essen GA, Stolker RJ, Kalkman CJ, Verheij TJ. The PINE study of epidural steroids and local anaesthetics to prevent postherpetic neuralgia: A randomised controlled trial. Lancet 2006; 367:219-224.

35. Higgins JP, Thompson SG. Quantifying heterogeneity in a meta-analysis. Stat Med 2002; 21:1539-1558.

36. Higgins JP, Thompson SG, Deeks JJ, Altman DG. Measuring inconsistency in meta-analyses. BM] 2003; 327:557-560.

37. Bowsher D. The effects of pre-emptive treatment of postherpetic neuralgia with amitriptyline: A randomized, double-blind, placebo-controlled trial. J Pain Symptom Manage 1997; 13:327-331.

38. Ji G, Niu J, Shi Y, Hou L, Lu Y, Xiong L. The effectiveness of repetitive paravertebral injections with local anesthetics and steroids for the prevention of postherpetic neuralgia in patients with acute herpes zoster. Anesth Analg 2009; 109:1651-1655.

39. Ahmed HE, Craig WF, White PF, Ghoname ES, Hamza MA, Gajraj NM, Taylor SM. Percutaneous electrical nerve stimulation: An alternative to antiviral drugs for acute herpes zoster. Anesth Analg 1998; 87:911-914.

40. Krcevski Skvarc N, Kamenik M. Effects of pregabalin on acute herpetic pain and postherpetic neuralgia incidence. Wien Klin Wochenschr 2010; 122:49-53.

41. Pasqualucci A, Pasqualucci V, Galla F, De Angelis V, Marzocchi V, Colussi R, Paoletti F, Girardis M, Lugano M, Del Sindaco F. Prevention of post-herpetic neuralgia: Acyclovir and prednisolone versus epidural local anesthetic and methylprednisolone. Acta Anaesthesiol Scand 2000; 44:910-918.

42. Alper BS, Lewis PR. Does treatment of acute herpes zoster prevent or shorten postherpetic neuralgia? J Fam Pract 2000; 49:255-264.

43. Jang YH, Lee JS, Kim SL, Chi SG, Lee WJ, Lee S-J, Kim S-W, Park KB, Lee WK, Jeon $\mathrm{YH}$, Kim DW. Do interventional pain Management procedures during the acute phase of herpes zoster prevent postherpetic neuralgia in the elderly?: A meta-analysis of randomized controlled trials. Ann Dermatol 2015; 27:771-774.

44. Balakrishnan S, Bhushan K, Bhargava VK, Pandhi P. A randomized parallel trial of topical aspirin-moisturizer solution vs. oral aspirin for acute herpetic neural- gia. Int J Dermatol 2001; 40:535-538.

45. Bruni L, Tagliapietra G, Innocenti P. Herpes zoster treatments: Results of a clinical trial relative to the use of rifamycin SV versus neuramide. J Int Med Res 1984; 12:255-260.

46. Liang L, Li X, Zhang G, Sun Y, Yu H, Jiao J. Pregabalin in the treatment of herpetic neuralgia: Results of a multicenter Chinese study. Pain Med 2015; 16:160-167.

47. Manabe H, Dan K, Hirata K, Hori K, Shono S, Tateshi S, Ishino H, Higa K. Optimum pain relief with continuous epidural infusion of local anesthetics shortens the duration of zoster-associated pain. Clin J Pain 2004; 20:302-308.

48. Xu G, Lv ZW, Xu GX, Tang WZ. Thiamine, cobalamin, locally injected alone or combination for herpetic itching: A single-center randomized controlled trial. Clin J Pain 2014; 30:269-278.

49. X G, Xu S, Cheng C, Xú G, Tang WZ, Xu J. Local administration of methylcobalamin and lidocaine for acute ophthalmic herpetic neuralgia: A single-center randomized controlled trial. Pain Pract 2016; 16:869-881.

50. Bareggi SR, Pirola R, De Benedittis G. Skin and plasma levels of acetylsalicylic acid: A comparison between topical aspirin/diethyl ether mixture and oral aspirin in acute herpes zoster and postherpetic neuralgia. Eur J Clin Pharmacol 1998; 54:231-235.

51. Hwang SM, Kang YC, Lee YB, Yoon KB, Ahn SK, Choi EH. The effects of epidural blockade on the acute pain in herpes zoster. Arch Dermatol 1999; 135:1359-1364.

52. Song SO, Yun JS, Lee DH. Is an epidural steroid injection with an addition of an intravenous and intradermal injection of lidocaine advantageous in the pain management of herpes zoster? Korean ] Anesthesiol 2002; 43:594-599.

53. Wang JS. The comparison of therapeutic effect of three methods for the treatment of acute herpes zoster. Current Opinion in Clinical Experimental Research 2002; 4:12-15.

54. Castelli M, Zanca A, Giubertoni G, Zanca A, Bertolini A. Griseofulvin-methisoprinol combination in the treatment of herpes zoster. Pharmacol Res Commun 1986; 18:991-996.

55. Dworkin RH, Barbano RL, Tyring SK, Betts RF, McDermott MP, PennellaVaughan J, Bennett GJ, Berber E, Gnann
JW, Irvine C, Kamp C, Kieburtz K, Max MB, Schmader KE. A randomized, placebo-controlled trial of oxycodone and of gabapentin for acute pain in herpes zoster. Pain 2009; 142:209-217.

56. Harding SP, Lipton JR, Wells JC, Campbell JA. Relief of acute pain in herpes zoster ophthalmicus by stellate ganglion block. Br Med J (Clin Res Ed) 1986; 292:1428.

57. Higa K, Hori K, Harasawa I, Hirata K, Dan K. High thoracic epidural block relieves acute herpetic pain involving the trigeminal and cervical regions: Comparison with effects of stellate ganglion block. Reg Anesth Pain Med 1998; 23:25-29.

58. Isbary G, Shimizu T, Zimmermann JL, Heinlin J, Al-Zaabi S, Rechfeld M, Morfill GE, Karrer S, Stolz W. Randomized placebo-controlled clinical trial showed cold atmospheric argon plasma relieved acute pain and accelerated healing in herpes zoster. Clinical Plasma Medicine 2014; 2:50-55.

59. Jensen-Dahm C, Rowbotham MC, Reda $H$, Petersen KL. Effect of a single dose of pregabalin on herpes zoster pain. Trials 2011; 12:55.

6o. Kanodia SK, Singhal KC. A study on efficacy of pregabalin in acute herpetic neuralgia. Ann Neurosci 2011; 18:148-150.

61. Kanodia SK, Seth AK, Dixit AM. Dose related efficacy of gabapentin in acute herpetic neuralgia among geriatric patients. Indian J Dermatol 2012; 57:362-365.

62. Lin $\mathrm{PL}$, Fan $\mathrm{SZ}$, Huang $\mathrm{CH}$, Huang $\mathrm{HH}$, Tsai MC, Lin CJ, Sun WZ. Analgesic effect of lidocaine patch $5 \%$ in the treatment of acute herpes zoster: A doubleblind and vehicle-controlled study. Reg Anesth Pain Med 2008; 33:320-325.

63. Stepanović A, Kolšek M, Kersnik J, Erčulj $\checkmark$. Prevention of post-herpetic neuralgia using transcutaneous electrical nerve stimulation. Wien Klin Wochenschr 2015; 127:369-374.

64. Tenicela R, Lovasik D, Eaglstein W. Treatment of herpes zoster with sympathetic blocks. Clin J Pain 1985; 1:63-67.

65. Fujii $\mathrm{H}$, Kosogabe $\mathrm{Y}$, Kajiki $\mathrm{H}$. The efficacy of intravenous lidocaine for acute herpetic pain-placebo controlled trial. Anesth Analg 2010; 110:S340.

66. Guo WJ, Xiao ZY, Yang YX. Effectiveness of transdermal fentanyl combined with clodine for pain control of acute herpes zoster. Journal of Dalian Medical University 2007; 29:255-256. 
67. Siedler S, Schuller-Petrovic S. Efficiency of enzyme combinations in the therapy of herpes zoster. $\mathrm{H}+\mathrm{G}$ Zeitschrift fur Hautkrankheiten 1999; 74:338-344.

68. Opstelten W, Van Wijck AJ, Van Essen GA, Buskens E, Bak AA, Kalkman CJ, Verheij TJ, Moons KG. The PINE study: Rationale and design of a randomised comparison of epidural injection of local anaesthetics and steroids versus careas-usual to prevent postherpetic neuralgia in the elderly [ISRCTN 32866390 ]. BMC Anesthesiol 2004; 4:2.

69. Opstelten W, van Wijck AJ, Moons KG, van Essen GA, Stolker RJ, Kalkman CJ,
Verheij TJ. Treatment of patients with herpes zoster by epidural injection of steroids and local anaesthetics: less pain after 1 month, but no effect on long-term postherpetic neuralgia: A randomised trial. Ned Tijdschr Geneeskd 2006; 150:2649-2655. 